\title{
An approach to value-based infrastructure asset management
}

Rengarajan Srinivasan BEng, MSc, PhD

Research Associate, Department of Engineering, University of Cambridge,

Cambridge, UK (corresponding author: rs538@cam.ac.uk)
Ajith Kumar Parlikad BEng, MSc, PhD

Senior Lecturer, Department of Engineering, University of Cambridge,

Cambridge, UK

Effective management of civil infrastructure assets requires intricate considerations with regard to safety, serviceability, reputation and cost. Additionally, infrastructure assets have different requirements from various stakeholders and have a longer service life. However, traditional asset management decisions focused predominantly on cost, and there is an inherent need to understand the value of an infrastructure asset to various stakeholders and to utilise this value to drive asset management decisions. In this paper, a systematic approach to making value-based asset management decisions is proposed. The proposed process provides an efficient method for mapping the stakeholder's requirements to the value provided by the asset. This map can then be used to assess the value and make effective decisions. The developed approach is demonstrated through a case study involving transportation tunnels. The essential consideration of value is expected to allow organisations to evaluate the balance between cost, risk and performance, thereby allowing better-informed decisions.

\section{Notation}

$B I_{\text {cor }}(t)$ total business impact due to rail corrosion for a given year $t$

$B I_{\text {sig }}(t)$ total business impact due to signalling disruption for a given year $t$

$D$ duration of disruption

$F \quad$ average number of fatalities

$I_{\mathrm{D}} \quad$ impact of disruption

$I_{R} \quad$ financial impact per fatality

$L \quad$ loss in revenue per customer

$N_{\mathrm{c}} \quad$ number of customers

$S_{\mathrm{D}} \quad$ service disruption

$S_{\mathrm{R}} \quad$ safety risk

$r \quad$ interest rate

Rep reputation

$w \quad$ weights

\section{Introduction}

Managing civil infrastructures is of vital importance for countries and has considerable socio-economic impact. The longer service life and ever-changing user demands pose distinct challenges in maintaining adequate service levels and reducing risks. Additionally, infrastructure assets are characterised by complex deterioration and interdependent systems, which makes decisionmaking a challenging task. Furthermore, civil infrastructure assets involve multiple stakeholders ranging from governments to end users (Chen et al., 2015). Reducing levels of available budget and the need to maintain a high level of service performance place considerable onus on asset owners to manage civil infrastructures effectively. Therefore, it is crucial for organisations to understand the value delivered by such civil infrastructure assets and to use this value to make asset management decisions.

Current asset management decisions are predominantly based on the principles of life cycle costing and are mainly focused on asset owners. These cost-based approaches lack consideration of various stakeholders associated with the asset. The value of an infrastructure asset depends on

a the benefits arising from the asset to the stakeholders by providing efficient service and effective performance

- the risk posed by the asset based on the operation and condition

- expenditure incurred by the asset over its life.

Systematic consideration of benefits realised through the asset while minimising risks and associated costs leads to value-driven asset management decisions. The current economic climate and shortage of funds are forcing asset owners to justify maintenance needs and also to look at innovative ways of managing assets and extending their life. Particularly for infrastructure assets, asset management solutions can include asset-specific or non-assetspecific approaches. For example, asset-specific solutions consist of the repair and refurbishment of assets, while non-asset-specific solutions for a bridge might include speed and weight restrictions. In order to determine the optimal strategy, it becomes imperative to understand the value.

Infrastructure assets seldom provide value on their own, but they contribute to the value generated at the system or network level. However, individual assets have the ability to affect the value generated by the system depending on their criticality to the service. For example, a bridge on its own does not deliver value, but the associated road network generates value for the users and the owners. The infrastructure assets are also highly dependent on other assets or systems. The impact of one asset will have an influence on the operation of other assets. This needs to be understood to develop effective asset management solutions.

Existing work in asset management focused on sector-specific issues such as water, pavement and municipal assets. Halfawy 
(2008) described the challenges associated with municipal infrastructure asset management and presented an integrated framework for managing the process and data fragmentation associated with multiple asset management silos. Management of pavements from a network-level perspective and the optimisation of pavement maintenance strategies have also been given considerable attention in the literature (Buttlar and Paulino, 2015; Zhang et al., 2012).

Research has also focused on understanding asset-specific solutions such as modelling the deterioration of assets and determining the optimal replacement or repair type/time. Micevski et al. (2002) developed a Markov model that represents the structural deterioration of storm water pipes and uses Bayesian techniques to convert data into model parameters. Similarly, Ana and Bauwens (2010) proposed statistics-based techniques for modelling the deterioration of urban drainage pipes. Han et al. (2014) applied a Bayesian estimation technique and a Markov hazard model to predict the deterioration of infrastructure assets.

Most of the existing works have focused on particular aspects of assets such as deterioration, while others have considered optimising the cost to determine the optimal maintenance policy or schedule. The importance of value-based asset management and what constitutes value are well defined (Institute of Asset Management, 2016). There has been lack of attention with regard to developing approaches focused on multiple stakeholders and to understanding the value generated by assets. The recent developments in the ISO 55000:2014 standard describe the need for value-based approaches (ISO, 2014a). However, there are no systematic approaches to identifying value and to making value-based decisions.

There have been considerable interests in multicriteria decisionmaking for infrastructure management (Kabir et al., 2014). These approaches allow consideration of various stakeholders' interests into a decision-making criterion. On the other hand, infrastructure assets not only have multiple stakeholders but also have various interdependencies between other assets that need to be taken into account. This has not been given considerable attention in the existing literature. In this paper, the authors propose a systematic approach to capturing the value generation process and to utilising this value to drive asset management decisions. The authors demonstrate the proposed approach by using a real case example involving transportation tunnels.
The paper is structured as follows: The section headed 'Value of an infrastructure asset' provides an illustration of the value generated by infrastructure assets. The section headed 'Process for value-driven asset management decision-making' describes the systematic process of value-driven asset management decisionmaking. The section headed 'Case study' presents the application of the proposed process in an industrial context, and the section 'Conclusions' concludes the paper.

\section{Value of an infrastructure asset}

In order to develop a value-based asset management, it is essential to understand what constitutes the 'value' of an infrastructure asset. This can be understood from the top-down and bottom-up perspectives. The top-down value is associated with organisationlevel aspects such as business model, while the bottom-up value is attributed to the asset or the asset systems and its functionality which allows value generation.

The business model and objectives of infrastructure organisations drive the different types of value required by various stakeholders. From the top-down perspective, the value generated by an infrastructure asset is attributed to the ability to deliver the intended functionality at the required level of performance while satisfying various stakeholders' objectives. It is important to note that the achievement of functionality needs to take place at the acceptable level of expenditure with clear understanding of the impending risks. Therefore, value-based asset management is about finding the optimal balance between cost, risks and the associated performance over the life cycle of the infrastructure.

On the other hand, the infrastructure asset or the network delivers value by meeting stakeholders' requirements enabled by safe and reliable services. One distinguishing factor related to infrastructure asset is that a single asset seldom provides value on its own. The value is provided by the infrastructure asset playing an effective role in a wider system or network of assets. For example, a bridge on its own does not deliver value, but the associated road network delivers value to different stakeholders. Additionally, infrastructure assets affect their value through their interactions with other assets in the system. Thus, it is essential to understand from the bottom up how an asset affects value directly or indirectly through its interactions with system-level assets. Table 1 compares the differences between the traditional costbased approach and the value-based approach.

Table 1. Comparison of cost-based and value-based asset management approaches

\begin{tabular}{|c|c|c|}
\hline & Cost-based (traditional) & Value-based (recommended) \\
\hline Core focus & Cost & Cost, risk and performance \\
\hline $\begin{array}{l}\text { Management } \\
\text { philosophy }\end{array}$ & $\begin{array}{l}\text { Minimise expenditure while maintaining } \\
\text { satisfying performance requirements }\end{array}$ & $\begin{array}{l}\text { Maximise performance while satisfying budgetary } \\
\text { constraints }\end{array}$ \\
\hline Stakeholder focus & Decision maker or asset owner & All stakeholders of the asset \\
\hline Impact on service & Maintain minimum service levels & Explore innovative approaches to improving service levels \\
\hline Difficulty & Well-established body of knowledge & Concepts not well understood \\
\hline Decision focus & Generally focuses on asset-specific issues & Focuses on system-level dependencies and business value \\
\hline
\end{tabular}


'Whole-life value' can be defined as 'the benefits, costs and risks associated with an asset over its whole-life by taking into account of the interests of all stakeholders affected by its construction, existence and usage and its wider economic, social and environmental impacts' (Hooper et al., 2009: p. xix).

The key to obtaining value is finding the critical balance between the costs and benefits of different renewal, maintenance and disposal interventions (Institute of Asset Management, 2015). The term 'whole-life value' is attributed to finding the best trade-off between short-term considerations and the conflicts of longer-term interests and objectives of various stakeholders. The ISO 55000:2014 standard proposes that realisation of the value will involve balancing costs, risks, opportunities and performance (ISO, 2014a). Furthermore, it is critical to interpret the term 'whole life' of an infrastructure. A typical life cycle consists of a number of stages such as requirement, design, build/procurement, operation and maintenance and disposal or end-of-life stages. From an infrastructure context, 'life' in general refers to the design life of the asset as defined by the designer or the manufacturer. However, many assets are operational for a duration longer than their designed life through effective interventions during their life. The decision-making horizon is influenced by various aspects, and the general consideration is to take into account of the period of responsibility of the asset (Institute of Asset Management, 2015). The decision-making horizon depends on the nature of the asset and the business model of the organisation. For instance, a contractor managing a set of assets will be interested in managing it for the contract duration. On the other hand, a county council managing a bridge might want to manage the asset over a longer period of 30 years or so. Therefore, it is essential to have a realistic understanding of the expected lifetime of the assets or the duration of the decision planning horizon. This could be

- the design life of asset

- the expected life of asset

- the planning horizon

- the decision-making horizon

- the regulatory cycle

- the contract duration.

Consequently, it is essential to understand the term 'whole life' better, depending on the nature of the decision, business driver of the organisation, regulatory or service contract requirements and the type of asset. The next section introduces a systematic process for making value-based asset management.

\section{Process for value-driven asset management decision-making}

The value-driven decision-making process consists of three stages and is shown in Figure 1. The three stages are
- stage A: establishment of the context
- stage B: value mapping
- stage $\mathrm{C}$ : value assessment.

Stage A is related to establishing the context under which valuebased decisions need to be made. This is important as there are different types of assets and problems associated with them.
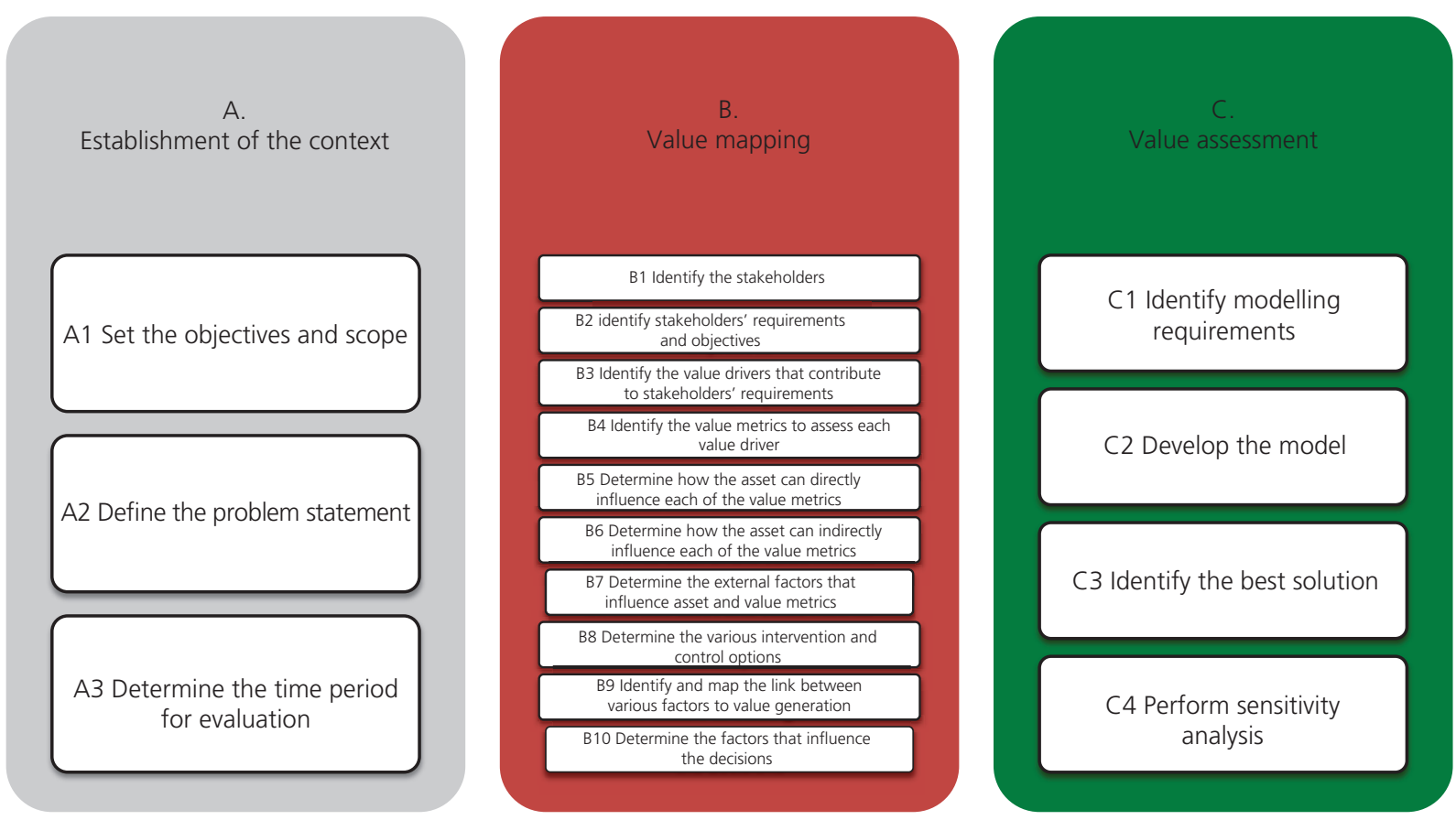

Figure 1. Systematic approach to value-based infrastructure asset management 
Typical asset management decisions vary widely depending on the context, asset type and their functionalities. These include determining optimal intervention decisions such as the time to repair, inspection and the type of repair to carry out. Other problem types include justification of funding requirements for regulatory compliance, scheduling of maintenance activities, portfolio management and prioritisation of maintenance tasks for a group of assets. Therefore, it is essential to establish the context. In this stage, the objective of the problem under consideration and the time period of evaluation are determined.

Stage B forms the core stage of the process as it establishes the value creation mechanisms. Each infrastructure asset generates value by providing functionality on its own or through interaction with other systems in the network. Consequently, any failure or disruption will have an impact on the value generated. The main objective of this stage is to understand the value and the associated risks contributed towards the various stakeholders requirements. The inclusion and analysis of the stakeholders' interest in asset management is one of the key guiding principles of the ISO 55001:2014 standard (see clause 4.2) (ISO, 2014b). Additionally, the impacts on the value either directly or indirectly associated with the asset are identified along with factors that can be used to control this value such as intervention options. The output of this stage is in the form of a map depicting how value is generated and the various interconnections that impact this value either positively or negatively. This value map will aid asset owners in understanding the various dependencies that need to be considered effectively when making decisions. Additionally, this value map will also indicate the typical information requirements for asset management.

Stage $\mathrm{C}$ is dedicated to value assessment and the associated decision-making aspect. It provides a systematic framework for developing a decision-making approach for calculating the value of the asset and the related impact of decisions on this value. Specifically, for infrastructure assets with long-term planning requirements, there is a need to conduct demand analysis for the asset under consideration. This will inform additional constraints on the value metrics as a function of time. The typical demand analysis of an infrastructure asset could include population dynamics and additional planned new infrastructure developments. The various decision options are evaluated based on value, and the decision maker can choose the best option that maximises the value. Additionally, the decision maker needs to understand the implication of decisions on the long-term value of the asset. The decision maker might need to evaluate the impending risk for postponing maintenance and/or restricting the use of the asset (such as speed or weight restrictions). The value assessment depends on the scope and objective of the problem under consideration. This can include evaluation of options or determination of the optimal intervention type and timing or prioritisation of the work schemes based on value.

In the next section, a case example is presented to illustrate the application of the proposed process in an industrial context.

\section{Case study}

\section{Introduction}

The case example concerns the development of an appropriate repair strategy for addressing seepages that occur in tunnels used for underground transportation. The proposed process is applied to this example to determine the repair option that provides the best value.

The seepages need not have an immediate impact on the structural integrity; however, they could have an impact on other assets such as signalling systems or rails. The impact of seepage depends on the location and extent of seepage and has varying degrees of consequences. In order to mitigate the risks posed by seepage, the asset manager has various repair options, each of which has a varying degree of success in minimising the seepage and will be effective for a fixed period of time. The current practice in the organisation for addressing the seepage problem was predominantly based on expert opinion and was subjective in nature. The aim was to develop an objective method that can be consistently used across the portfolios of tunnels rather than being case-specific. The next subsection illustrates the application of the value-based decision-making process to this problem.

\section{Stage A: establishment of the context}

The main objective was to determine the best repair option for the tunnel seepage problem that would achieve the best value for money and has the least business impact. The repair option that yields the lowest service disruption, low safety risk and low financial impact is the optimal strategy. The time period of evaluation was 30 years, consistent with the long-term planning horizon of the asset owner.

\section{Stage B: value mapping}

In the second stage, the value generation process is captured in the form of a map depicting the factors that influence the value generated by the tunnels to the various stakeholders. The value mapping process was carried out through a series of workshops with experts from different parts of the organisations such as operations, maintenance and civil assets group.

The first step in this stage is to identify the various internal and external stakeholders associated with tunnels. The vital internal stakeholders were the different business units of the organisation such as operations, maintenance and internal regulators. The external stakeholders were the customers using the tunnel, the government regulator and the mayor of the city. The next step was to identify the requirements and objectives of each of the identified stakeholders. Most requirements from the stakeholders were in relation to the effectiveness of the service provided, safety and the costs incurred. From the asset owners' perspective, in addition to service delivery, the reputation of the organisation was one of the important requirements. Additionally, the mayor of the city was interested in the reputation and the ambience was also paramount.

The various value drivers were identified based on categorisation of the various stakeholders' requirements. The essential categories for 
the value drivers are related to service delivery, safety, costs, sustainability and reputation. In order to assess the value drivers, various metrics were established. To assess safety, accident frequency, passenger fatalities and causalities were identified as metrics. Similarly, for assessing the service risk, lost customer hours and service reliability were used as metrics. The amount of media coverage, measured in column inches, was used to assess the reputation value driver. It was further possible to convert all the value metrics into monetary terms for the purposes of asset management decisions, and this was part of risk quantification to drive intervention decisions.

The next step was to identify the factors that influence the value generated by the tunnels. In other words, the main aim of this step is to identify how the value generated by the system is affected by seepages in the tunnel. This is related to the various ways in which the functionality provided by the tunnels is affected. This was identified by existing maintenance practices and the guidance developed by the asset owner. The tunnel can directly affect the value through normal structural deterioration to complete collapse. The seepage-related problems affect the value based on the location in the tunnel and includes tunnel lining, lining joints and through head walls. In this particular example, the focus is on seepages occurring in tunnel lining joints. Seepages in general do not directly affect value, but have an influence due to their interaction with other systems. For instance, seepage occurring in tunnel lining joints will impact signalling systems, which in turn can cause service delays and will impact on the reputation of the organisation. On the other hand, seepages can also cause corrosion of rails and in this case will lead to service disruptions and have safety implications for the tunnel operator.

Additionally, external factors such as weather and geology will have an impact on how seepages occur in the tunnel. For example, depending on the soil type, excessive rainfall will cause seepages in the tunnels. Furthermore, external construction activities and other events in the vicinity of the tunnel can cause excessive ground movements, leading to structural integrity issues and possibly to tunnel weakening.

The next step is to identify the various intervention and control options that can be used to reduce the risk and maximise the value. This includes different inspection techniques, repair options and temporary mitigation solutions. Principal and special inspections were identified as mechanisms for assessing the condition of the tunnel and can be used to determine the optimal time to repair. The main repair strategies for seepage in tunnels were face sealing, acrylic grouting, polyurethane (PU) grouting and lead caulking. Temporary solutions such as water management systems can be used to mitigate the risk of seepage affecting other assets. Finally, the factors that affect the decisions were identified. In the specific case of seepage in tunnels, the location of the tunnel in the network and the criticality of the network (based on the number of passengers carried) will have an impact on the repair strategy. Further, heritage status and political factors need to be considered when deciding the optimal repair strategy for the seepage problem. Figure 2 shows the typical value map for the tunnel focusing on the seepage problem occurring in lining joints.

\section{Stage C: value assessment}

The next stage in the process is to assess the value to determine the best repair option for the seepage problem. The first step in the assessment stage is to identify the essential modelling requirements from the value map. The key value-influencing factors that need to be modelled are the signalling disruptions and the corrosion of rails. For the particular case of the seepage-related problem, it is reported either during inspection or during the maintenance of other assets. Therefore, this is a reactive maintenance strategy and the objective is to choose the best repair option that would either eliminate the seepage problem or minimise it. For each of the factors that influence value, suitable value metrics are identified based on the value map. Signalling disruptions have an impact on service reliability, reputation and costs, whereas the corrosion of rails impacts service reliability, safety and costs. This needs to be taken into account when deciding the repair option depending on what other assets are being affected. Additionally, the demand on the tunnel (number of passengers) is assumed to be constant over the time period under consideration.

In order to assess the overall value for each repair strategy, the weighted sum of the individual value metrics is used to determine the best choice. The combined weighted sum indicates the total business impact on the organisation, and the best repair option is the one which has the least business impact. Based on the modelling requirements, the factors that need to be modelled are

- the impact of signalling disruptions and rail corrosion due to seepage on service, safety, reputation and costs

- the impact of various repair options on the different value metrics.

\section{Quantifying service disruption}

Service disruption is attributed to full or partial closure of the line and is determined by the duration of disruption $(D)$ and the impact of disruption $I_{\mathrm{D}}$. Additionally, the impact of disruption is loss in revenue per customer $L$ times the average number of customers $\left(N_{\mathrm{c}}\right)$

1. $S_{\mathrm{D}}=D I_{\mathrm{D}}=D L N_{\mathrm{c}}$

The impact of disruption will depend on the location of the tunnel in the network and its strategic importance. In this particular case example, $L$ is $£ 8.82$ per customer and the average number of customers per hour is 3260 . Therefore, the impact of $1 \mathrm{~h}$ of service disruption is $£ 28750$.

\section{Quantifying safety risk}

Safety issues arise due to derailments attributed to corrosion on tracks and depend on the average number of fatalities $(F)$ for the network associated with the tunnel and the financial impact per fatality $\left(I_{\mathrm{R}}\right)$ 


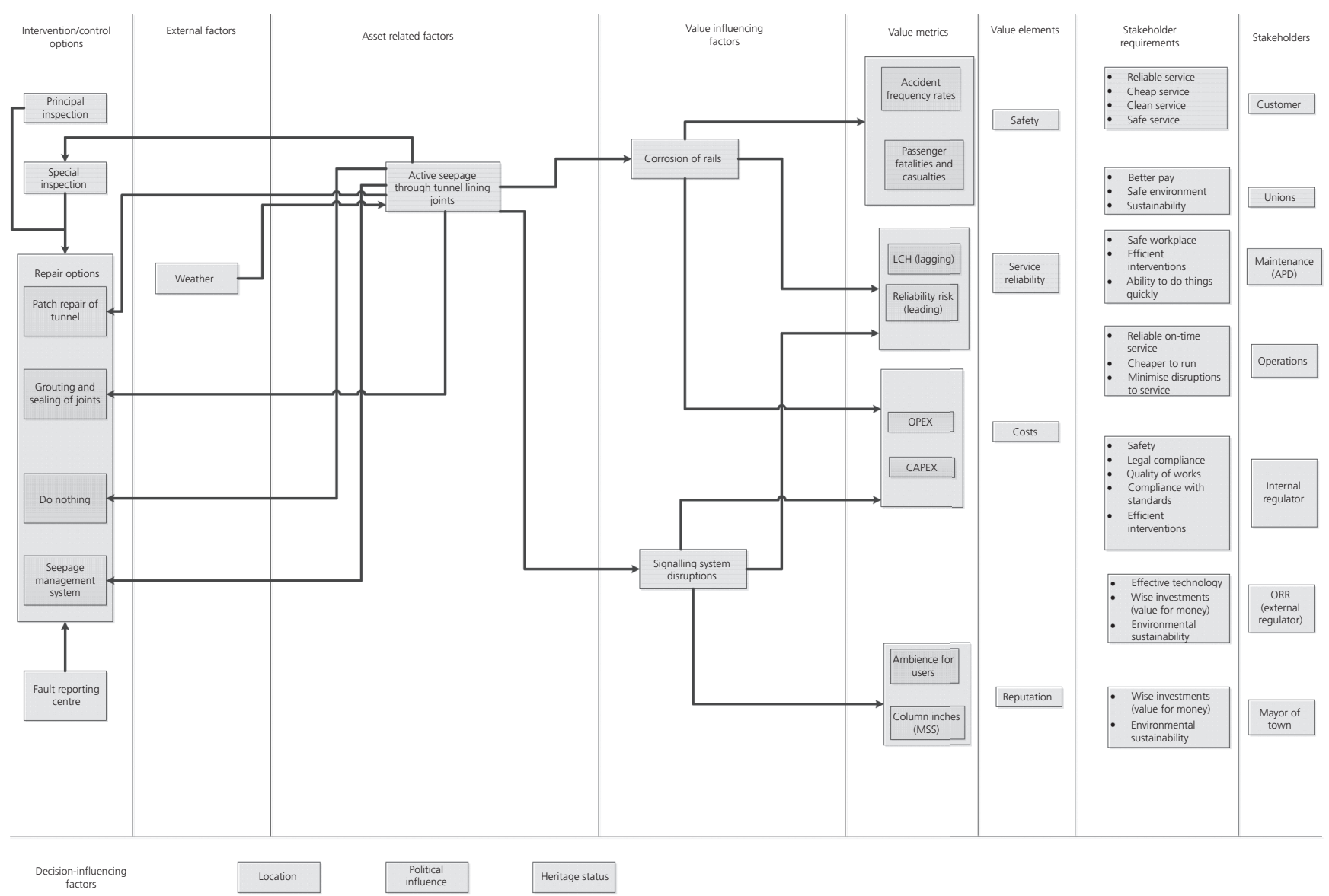

Figure 2. Value map for the seepage problem occurring in tunnels. APD, asset performance directorate; Capex, capital expenditure; LCH, lost customer hours; MSS, mystery shopper survey; Opex, operating expense; ORR, office of rail regulator

2. $S_{\mathrm{R}}=F I_{\mathrm{R}}$

In this particular example $F=0.0054$ was calculated using historical data and $I_{\mathrm{R}}$ was $£ 1.728$ million. Therefore, the safety risk was $S_{\mathrm{R}}=£ 9439$.

\section{Quantifying reputation}

The impact of reputation due to signalling disruptions is based on the amount of media coverage for the incident. In this particular example, it was assumed that the reputation was linearly proportional to the service impact by about $1 / 10$
3. $\operatorname{Rep}=\frac{S_{\mathrm{D}}}{10}$

\section{Modelling the intervention options}

In order to address the seepage problem, four different repair options were considered, and these are presented in Table 2. Active seepage in tunnel lining joints requires the repair to be carried out on average between three and five joints, and the total cost is indicated in the second row. Each of the repair options is effective only for a certain fixed time period as shown in the fourth row of the table. Based on the time period of evaluation,

Table 2. Intervention options

\begin{tabular}{lccrr} 
& Option $\mathbf{1}$ & Option 2 & Option 3 & Option 4 \\
\hline Repair type & Face sealing & Acrylic grouting & PU grouting & Lead caulking \\
Cost per joint: $f$ & 500 & 1050 & 1050 & 3000 \\
Total cost: $f$ & 2500 & 5250 & 5250 & 15000 \\
Effectiveness: years & 1 & 10 & 100 & 1000 \\
Number of repairs & 30 & 3 & 75 & 1 \\
Risk reduction: \% & 50 & 70 & & 90
\end{tabular}


this will have an impact on the number of repairs that need to be done and is shown in the fifth row. The last row represents the likelihood of seepage not occurring in the next year.

\section{Assessing total business impact}

The whole-life value is assessed as a measure of the total business impact due to disruptions causes by seepages in the tunnels. The total business impact is the weighted sum of individual value drivers. The total business impact due to signalling disruption for a given year $t$ is calculated as

4. $B I_{\mathrm{Sig}}(t)=w_{1} S_{\mathrm{D}}(t)+w_{2} R_{\mathrm{ep}}(t)+w_{3} \operatorname{Cost}(t)$

Similarly, the total business impact due to corrosion of rails caused by seepage for a given year $t$ is given as

5. $B I_{\text {cor }}(t)=w_{1} S_{\mathrm{D}}(t)+w_{3} \operatorname{Cost}(t)+w_{4} S_{\mathrm{R}}(t)$

where $w_{1}, w_{2}, w_{3}$ and $w_{4}$ are the relative weights for service, reputation, cost and safety, respectively. Each of the repair options will have a different impact on the various value metrics; therefore, the business impact will be different for all the repair options. This reflects the amount of risk reduced by a particular repair option and the resulting reduction in the associated total business impact.

For the whole-life value for an evaluation period of $N=30$ years, the total business impact can be calculated as

6. $B I_{\mathrm{Sig}}(\mathrm{OPT})=\sum_{i=1}^{N} \frac{B_{\mathrm{ISig}}(i)}{(1+r)^{i}}$

7. $B I_{\mathrm{Cor}}(\mathrm{OPT})=\sum_{i=1}^{N} \frac{B_{\mathrm{ICor}}(i)}{(1+r)^{i}}$

where OPT refers to each of the repair options shown in Table 2 and $r$ is the discount rate. Equations 6 and 7 represent the discounted sum of the business impact for $N$ years, and $r=3 \%$ is used in this particular example. Equations 6 and 7 can be used to assess the business impact per year and the total business impact for the decision horizon. Tables 3 and 4 show the relative impact of service, safety, reputation and cost for signalling disruptions and rail corrosion due to seepage. Equal weights for each of the value drivers have been used in this case example. It can be seen that in both cases the lead caulking is the best repair option. This because of the fact that lead caulking reduces the risk of seepage occurring consequently (about 90\%).

\section{Sensitivity analysis}

The impact of service reliability on the repair options vary depending on the location of the tunnel in the network. Furthermore, service impact has significant business consequences for the organisation; therefore, the service impact is varied and the total business impact is calculated for each of the option. The change in the service impact is directly related to the criticality of the tunnel in the network and indicates the different lines that operate in the various tunnel networks. This is based on the location of the tunnel and the number of passengers carried in a particular line. Figure 3(a) illustrates the impact of various operating lines on the different repair options. For signalling disruptions due to seepages occurring in lines 6 and 5, option 2 (acrylic grouting) is the preferred choice. For all other lines, option 4 (lead caulking) is the best option because the lines are critical to the network. However, from Figure 3(b), it can be seen that lead caulking is the best option for seepages causing corrosion on rails, as it has significant impact on service and safety risks. Using sensitivity analysis on service impact, the organisation can understand the relation between the criticality of the network and the best repair option for tackling seepages.

One of the other challenges in infrastructure management is the need for understanding short-term decision impact against longterm planning. To understand this effect, the time period of analysis is varied and the resulting business impact for the various repair options for the signalling disruption is calculated, and this is shown in Figure 4. From the figure, it can be seen that acrylic grouting is the best repair option when the time period of analysis is less than $12 \cdot 2$ years. When the decision horizon is longer, then lead caulking is the preferred repair option that will have the least business impact for signalling disruption due to seepages. Using this analysis, the organisation can plan for the best repair option depending on the funding available and offers flexibility in managing the seepage problems. On the other hand, the organisation can use such analysis to justify the need for longterm planning and the associated budget requirements for regulators.

Table 3. Results for signalling disruptions

\begin{tabular}{|c|c|c|c|c|}
\hline & Option 1 & Option 2 & Option 3 & Option 4 \\
\hline Service: $f$ & 290209 & 174125 & 145105 & 116084 \\
\hline Reputation: $f$ & 29020 & 17412 & 14510 & 11608 \\
\hline Cost: $f$ & 50471 & 12603 & 5250 & 15000 \\
\hline Total impact: $f$ & 369701 & 203601 & 164865 & 142692 \\
\hline
\end{tabular}

Bold indicates the particular option with least business impact 
Table 4. Results for corrosion of rails

\begin{tabular}{lrrrr} 
& Option 1 & Option 2 & Option 3 & Option 4 \\
\hline Service: $f$ & 156461 & 93876 & 78230 & 62584 \\
Safety: $f$ & 95281 & 57168 & 47640 & 38112 \\
Cost: $f$ & 50471 & 12603 & 5250 & 15000 \\
Total impact: $\mathrm{f}$ & 312800 & 169461 & 136414 & $\mathbf{1 1 9}$ \\
\hline
\end{tabular}

Bold indicates the particular option with least business impact

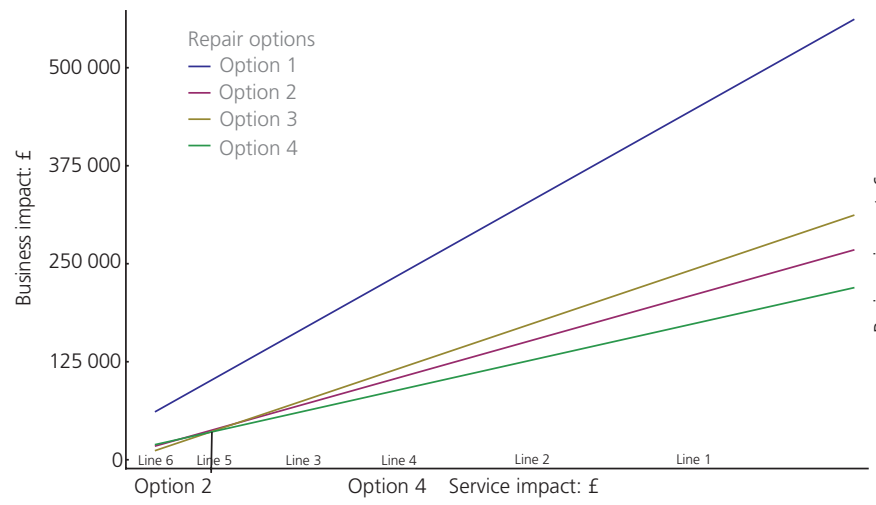

(a)

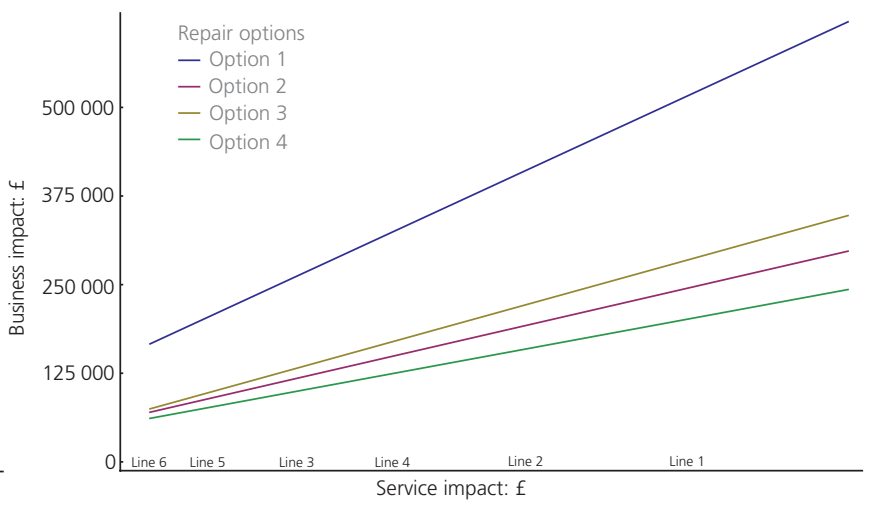

(b)

Figure 3. Sensitivity analysis on service reliability: impacts of service on (a) signalling disruption and (b) corrosion of rails

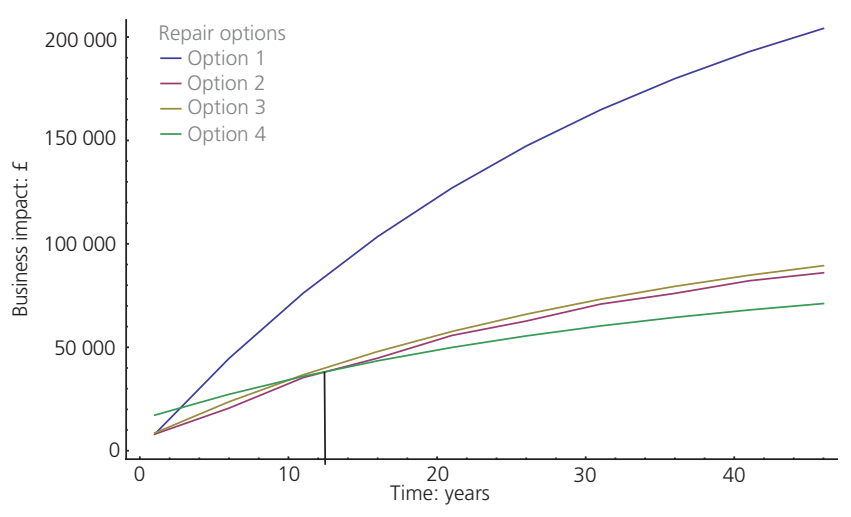

Figure 4. Impact of time period of analysis on signalling disruptions due to seepage

\section{Conclusions}

Infrastructure asset management is becoming more critical for organisations, particularly in providing high-quality service with an increasingly stringent budget. Additionally, there is a need to manage infrastructure assets to meet the varying demands of various stakeholders. A value-based infrastructure asset management decision-making process is proposed, which can be used to identify systematically the value generation process and to incorporate this value into asset management decisions. The proposed approach takes into account the various stakeholders' requirements, and a map representing the flow of value is developed. This value map can then be used to develop innovative ways of managing assets with clear understanding of the interdependent systems and the implication of intervention decisions. The proposed process was demonstrated through a case example concerning the identification of the best repair option to mitigate the risks posed by seepages that occur in tunnels.

\section{Acknowledgements}

The research work was performed within the context of SustainOwner ('Sustainable Design and Management of Industrial Assets through Total Value and Cost of Ownership'), a project sponsored by the EU Framework Programme Horizon 2020, MSCARISE-2014: Marie Skłodowska-Curie Research and Innovation Staff Exchange (Rise) (grant agreement number 645733 - Sustain-owner H2020-MSCA-RISE-2014). The research was funded by the Engineering and Physical Sciences Research Council Innovation and Knowledge Centre for Smart Infrastructure and Construction at the University of Cambridge.

\section{REFERENCES}

Ana EV and Bauwens W (2010) Modeling the structural deterioration of urban drainage pipes: the state-of-the-art in statistical methods. Urban Water Journal 7(1): 47-59, http://dx.doi.org/10.1080/ 15730620903447597.

Buttlar WG and Paulino GH (2015) Integration of Pavement Cracking Prediction Model with Asset Management and Vehicle-Infrastructure Interaction Models. US Department of Transportation, Washington, DC, USA.

Chen L, Henning TF, Raith A and Shamseldin AY (2015) Multiobjective optimization for maintenance decision making in infrastructure asset 
management. Journal of Management in Engineering 31(6): 4015015-1.

Halfawy MR (2008) Integration of municipal infrastructure asset management processes: challenges and solutions. Journal of Computing in Civil Engineering 22(3): 216-229, http://dx.doi.org/10 1061/(ASCE)0887-3801(2008)22:3(216).

Han D, Kaito K and Kobayashi K (2014) Application of Bayesian estimation method with Markov hazard model to improve deterioration forecasts for infrastructure asset management. KSCE Journal of Civil Engineering 18(7): 2107-2119, http://dx.doi.org/10.1007/s12205-0120070-6.

Hooper R, Armitage R, Gallagher A and Osorio T (2009) Whole-life Infrastructure Asset Management: Good Practice Guide for Civil Infrastructure. Construction Industry Research and Information Association, London, UK.

Institute of Asset Management (2015) Asset Management - an Anatomy. Institute of Asset Management, Bristol, UK.
Institute of Asset Management (2016) Subject Specific Guidance: Capital Investment, Operations and Maintenance Decision Making. Institute of Asset Management, Bristol, UK.

ISO (International Organization for Standardization) (2014a) ISO 55000:2014: Asset management. ISO, Geneva, Switzerland.

ISO (2014b) ISO 55001:2014: Asset management - management systems - requirements. ISO, Geneva, Switzerland.

Kabir G, Sadiq R and Tesfamariam S (2014) A review of multi-criteria decision-making methods for infrastructure management. Structure and Infrastructure Engineering 10(9): 1176-1210, http://dx.doi.org/10. 1080/15732479.2013.795978.

Micevski T, Kuczera G and Coombes P (2002) Markov model for storm water pipe deterioration. Journal of Infrastructure Systems 8(2): 49-56.

Zhang H, Keoleian GA and Lepech MD (2012) Network-level pavement asset management system integrated with life-cycle analysis and life-cycle optimization. Journal of Infrastructure Systems 19(1): 99-107.

\section{How can you contribute?}

To discuss this paper, please submit up to 500 words to the editor at journals@ice.org.uk. Your contribution will be forwarded to the author(s) for a reply and, if considered appropriate by the editorial board, it will be published as discussion in a future issue of the journal. 